\title{
Entomological indices of malaria transmission in Chikhwawa district, Southern Malawi
}

Themba Mzilahowa ${ }^{1,2,3^{*}}$, lan M Hastings ${ }^{1}$, Malcolm E Molyneux ${ }^{1,2,3}$ and Philip J McCall ${ }^{1}$

\begin{abstract}
Background: Although malaria is highly prevalent throughout Malawi, little is known of its transmission dynamics. This paper describes the seasonal activity of the different vectors, human biting indices, sporozoite rates and the entomological inoculation rate in a low-lying rural area in southern Malawi.

Methods: Vectors were sampled over 52 weeks from January 2002 to January 2003, by pyrethrum knockdown catch in two villages in Chikhwawa district, in the Lower Shire Valley.

Results: In total, 7,717 anophelines were collected of which 55.1\% were Anopheles gambiae sensu lato and 44.9\% were Anopheles funestus. Three members of the An. gambiae complex were identified by PCR: Anopheles arabiensis (75\%) was abundant throughout the year, An. gambiae s.s. (25\%) was most common during the wet season and Anopheles quadriannulatus occurred at a very low frequency $(n=16)$. An. funestus was found in all samples but was most common during the dry season.

Anopheles gambiae s.s. and An. funestus were highly anthropophilic with human blood indices of $99.2 \%$ and $96.3 \%$, respectively. Anopheles arabiensis had fed predominantly on humans (85.0\%) and less commonly on cattle (10.9\%; $1.2 \%$ of blood meals were of mixed origin). Plasmodium falciparum $(192 / 3,984)$ and Plasmodium malariae $(1 / 3,984)$ sporozoites were detected by PCR in An. arabiensis (3.2\%) and An. funestus (4.5\%), and in a significantly higher proportion of An. gambiae s.s. $(10.6 \%)(p<0.01)$. All three vectors were present throughout the year and malaria transmission occurred in every month, although with greatest intensity during the rainy season (January to April). The combined human blood index exceeded $92 \%$ and the $P$. falciparum sporozoite rate was $4.8 \%$, resulting in estimated inoculation rates of 183 infective bites/ person per annum, or an average rate of $\sim 15$ infective bites/ person/month.
\end{abstract}

Conclusions: The results demonstrate the importance of An. gambiae s.S., An. arabiensis and An. funestus in driving the high levels of malaria transmission in the south of Malawi. Sustained and high coverage or roll out of current approaches to malaria control (primarily insecticide-treated bed nets and indoor residual house spraying) in the area are likely to reduce the observed high malaria transmission rate and consequently the incidence of human infections, unless impeded by increasing resistance of vectors to insecticides.

Keywords: Malaria, Africa, Malawi, Plasmodium, Anopheles, falciparum, Malariae, Gambiae, Transmission, EIR

\footnotetext{
* Correspondence: tmzilahowa@gmail.com

${ }^{1}$ Liverpool School of Tropical Medicine, Liverpool, Pembroke Place, UK

${ }^{2}$ Malawi-Liverpool Wellcome Trust Clinical Research Programme, Blantyre,

Malawi

Full list of author information is available at the end of the article
}

\section{Biomed Central}

(c) 2012 Mzilahowa et al.; licensee BioMed Central Ltd. This is an Open Access article distributed under the terms of the Creative Commons Attribution License (http://creativecommons.org/licenses/by/2.0), which permits unrestricted use, distribution, and reproduction in any medium, provided the original work is properly cited. 


\section{Background}

Malaria is highly endemic and prevalent throughout Malawi, with two thirds of the total population of 12 million people at direct risk of the infection $[1,2]$. Over $18 \%$ of hospital deaths of children less than five years old, and over one third of all outpatient visits, are attributed to malaria [1], the most highly prevalent parasite species being Plasmodium falciparum. While there has been substantial research in Malawi on the pathology and chemotherapy of malaria, little is known of malaria transmission dynamics and of the vectorial roles of various anopheline species known to occur in Malawi.

Malaria transmission in Africa is dominated by the Anopheles gambiae species complex and the Anopheles funestus group of mosquitoes. Studies on malaria transmission in Malawi began in 1911, when two vectors were identified: An. funestus which was the most common, and An. gambiae s.l. (referred to as Anopheles costalis) [3]. Later studies by Lamborn [4] and Berner [5] recorded that while An. funestus was abundant throughout the year, An. gambiae s.l. was found only in the wet season. In 1992, Hawley et al. [6] surveyed districts in the southern (Nsanje and Mangochi) and central (Dowa) regions of Malawi over a four month period in dry and wet seasons. They confirmed the presence of An. funestus and A. gambiae s.l. and, for the first time, identified both An. gambiae sensu stricto (s.s.) and Anopheles arabiensis in all three sites. Spiers et al. [7] recorded $A n$. gambiae s.s., An. arabiensis, Anopheles merus and Anopheles quadriannulatus (the latter two species in very low numbers); An. arabiensis was the predominant anopheline species, comprising over $80 \%$ of adult collections. Plasmodium falciparum sporozoites have been detected in An. gambiae s.s., An. arabiensis and An. funestus $[6,8]$ and all three mosquitoes have been shown also to be vectors of Wuchereria bancrofti in Malawi [9]. The absence of more comprehensive transmission data for Malawi remains an obvious knowledge gap [10], particularly in an era when reducing transmission is increasingly recognized as an important component of malaria control and a necessary step toward eventual elimination of the infection [11].

Malawi's malaria control programme is supported by the Global Fund and the US government's President's Malaria Initiative (PMI). An initial aim was to reach universal coverage with indoor residual spraying (IRS) by 2011 [12], since such a strategy has proved to be highly effective in some settings [13]. Any optimism must, however, be tempered by reports of resistance to pyrethroids in populations of both the An. gambiae and An. funestus complexes in southern Malawi [14,15].

To provide basic data on the entomological indices of malaria transmission in southern Malawi, we undertook a study on malaria transmission in the Lower Shire
Valley, an area of intense year round malaria transmission. Insight into the genetic structure of P. falciparum using data derived from infections in vectors collected from that study has already been reported [16], and here we describe the relative importance of different mosquito species in transmission, their human biting rates and the entomological inoculation rate for malaria in a rural area in southern Malawi.

\section{Methods}

\section{Study area}

The study was carried out in Chikhwawa district $\left(16^{\circ} 1^{\prime}\right.$ S; $34^{\circ} 47^{\prime}$ E), in the Lower Shire Valley, southern Malawi. Based on hospital in-patient records, this area was assumed to have perennial malaria transmission. The area has been a focus of studies investigating malariarelated anaemia, P. falciparum genetics and lymphatic filariasis [9,17-19]. Chikhwawa is approximately $70 \mathrm{~m}$ above sea level, divided throughout its length by the Shire River (the largest river in Malawi) and prone to flooding in the wet season. The area has a tropical climate with a mean annual temperature of $26^{\circ} \mathrm{C}$, a single wet season from November to April, and annual rainfall of approximately $770 \mathrm{~mm}$ (Malawi Meteorological Office, Chileka, Blantyre). There are extensive rice and sugarcane irrigation schemes.

Following consultation with the District Environmental Health Officer (DEHO) and on the basis of accessibility by road and similarity to other villages in the area, two study villages were selected: Chipula ( $15^{\circ} 59^{\prime} 33^{\prime \prime} \mathrm{S}$; $34^{\circ} 47^{\prime} 22^{\prime \prime} E$ ) to the west of the Shire River and north of Chikhwawa District centre (with 109 households), and Kela (16 02' 72" S; 34 50' 52" E) (with 117 households) situated to the east of the Shire river. At both villages, the human population lived in thatched brick homes and engaged in subsistence agriculture. Two crops of maize were grown per year. Fishing was common, particularly in Kela, which is situated on the edge of a lake. Some households owned cattle (approximately 50 and 20 animals at Chipula and Kela, respectively) or goats, the majority of which were held in large communal kraals overnight.

At the time of the study, organized vector control in this area had not yet been implemented; few households used insecticide-treated bed nets and indoor residual spraying or other approaches were not in use.

\section{Mosquito collection}

Sampling of adult anopheline mosquitoes was carried out weekly over a period of 52 weeks, from January 2002 to January 2003. Permission to work in the villages was first sought from the village chiefs and householders during community sensitization meetings. Later and during each visit, collections were only carried out after 
the household owner had provided their free and informed consent to do so. All households were listed at the beginning of the study. Microsoft Excel was used to randomly select individual households, with replacement. To avoid excessive intrusion into the participants' homes, three new houses were selected at each subsequent visit and a house could be re-visited only after a month. The right to refuse or withdraw at any time was respected. Where permission to enter a house was refused, an alternative house in the immediate proximity was selected.

Collection of mosquitoes was carried out between 6:00 a.m. and 8:00 a.m. Preparation of houses and mosquito collection followed standard procedures [20]. The owners were requested to refrain from sweeping until after collection, and all food items, cooking utensils and water were moved outside during the exercise. White sheets were laid in the rooms to cover the floors, beds and other flat surfaces. The interior space of the house was then sprayed with a pyrethroid-based household insecticide aerosol 'Doom' (Dichlorvos, Tetramethrin and dPhenothrin; Robertsons Homecare Ltd, South Africa) [20]. The eaves and windows were sprayed simultaneously on the outside. The house was exited and doors closed. The sheets were removed for inspection after 10-15 minutes.

All mosquitoes were collected and placed in petri dishes lined with a damp filter paper. Mosquito samples from the 3 houses were kept in separate petri dishes and labeled accordingly. Petri dishes were put in a cooler box and transported to the laboratory in Blantyre for processing.

\section{Mosquito analyses}

Freshly collected anophelines were identified initially using a morphological key [21,22]. Mosquito blood meals were taken from a sub-sample of up to 20 freshly fed mosquitoes per house for subsequent host identification, by crushing individual abdomens onto Whatman ${ }^{\circledR}$ filter papers (No. 3; $110 \mathrm{~mm}$ diameter), that were stored in plastic bags containing silica gel until analysis. Abdomens of remaining mosquitoes were then removed and dissected to examine midguts for oocysts [16]. Heads and thoraces of all collected mosquitoes were stored in $1.5 \mu \mathrm{l}$ eppendorf tubes and stored over silica gel for subsequent examination for Plasmodium spp. sporozoites.

\section{Identification of species within the An. gambiae species complex}

Anopheles cytospecies were identified using ribosomal DNA extracted with LIVAK lysis buffer from individual mosquitoes followed by DNA amplification by the standard rDNA-PCR method [23,24]. If the initial PCR test failed to amplify for a sample, it was repeated twice until successful amplification occurred, or was scored as unknown. Reactions included negative and positive controls. All reactions were carried out using the GeneAmp ${ }^{\circledR}$ PCR System 2700 (Applied Biosystems, UK).

\section{Analysis of blood meals}

A direct enzyme-linked immunosorbent assay (ELISA) was used to identify the source of mosquito blood meals [25]. Each sample was analysed by two separate assays: one for human blood and one for bovine blood. Positive results were read visually, 30 minutes after adding the substrate ABTS (2,2। azino-bis 3-ethylbenzthiazoline-6sulphonic acid) and hydrogen peroxide (Kirkegaard and Perry Laboratories, USA) in a 1:1 mixture ratio. A subsample of 100 positive specimens was re-run for each test to confirm the test.

\section{Detection of Plasmodium spp. sporozoites}

Plasmodium spp. sporozoites were detected and identified by PCR on DNA extracts from heads and thoraces of individual female mosquitoes [26]. DNA was extracted [23] and diluted to $10 \%$ in water for optimal PCR amplification. PCR reactions were performed using the Applied Biosystems, GeneAmp ${ }^{\circledR}$ PCR System 2700 thermocycler. The cycling parameters were: step $1,95^{\circ} \mathrm{C}$ for 5 minutes; step $2,94^{\circ} \mathrm{C}$ for 1 minute, annealing at $58^{\circ} \mathrm{C}$ for 2 minutes, extension at $72^{\circ} \mathrm{C}$ for 2 minutes; step 3 , final extension at $72^{\circ} \mathrm{C}$ for 5 minutes.

\section{Climate data}

Climate data measured at Kasinthula irrigation project $\left(16^{\circ} 5^{\prime} \mathrm{S}, 34^{\circ} 49^{\prime} \mathrm{E}\right.$; the nearest weather station to the study sites) was obtained from the central meteorological offices at Chileka International Airport in Blantyre. Monthly mean rainfall, and daily mean, maximum and minimum temperatures were recorded (Figure 1).

\section{Data analyses}

Data were analysed using SPSS version 12.0.1. Proportions were compared using Chi-Square test, or Fisher's Exact test where appropriate. The entomologic inoculation rate (EIR) was calculated from the mean numbers of blood-fed mosquitoes (number of mosquitoes divided by the number of house occupants, multiplied by the human blood index for each mosquito species) multiplied by the sporozoite rates. The estimated annual EIR was the sum of the monthly means for the three vectors.

\section{Ethical issues}

Ethical permission for the study was provided by the Research Ethics Committees of the College of Medicine Blantyre (COMREC) and the Liverpool School of Tropical Medicine. Permission to work in specific villages 


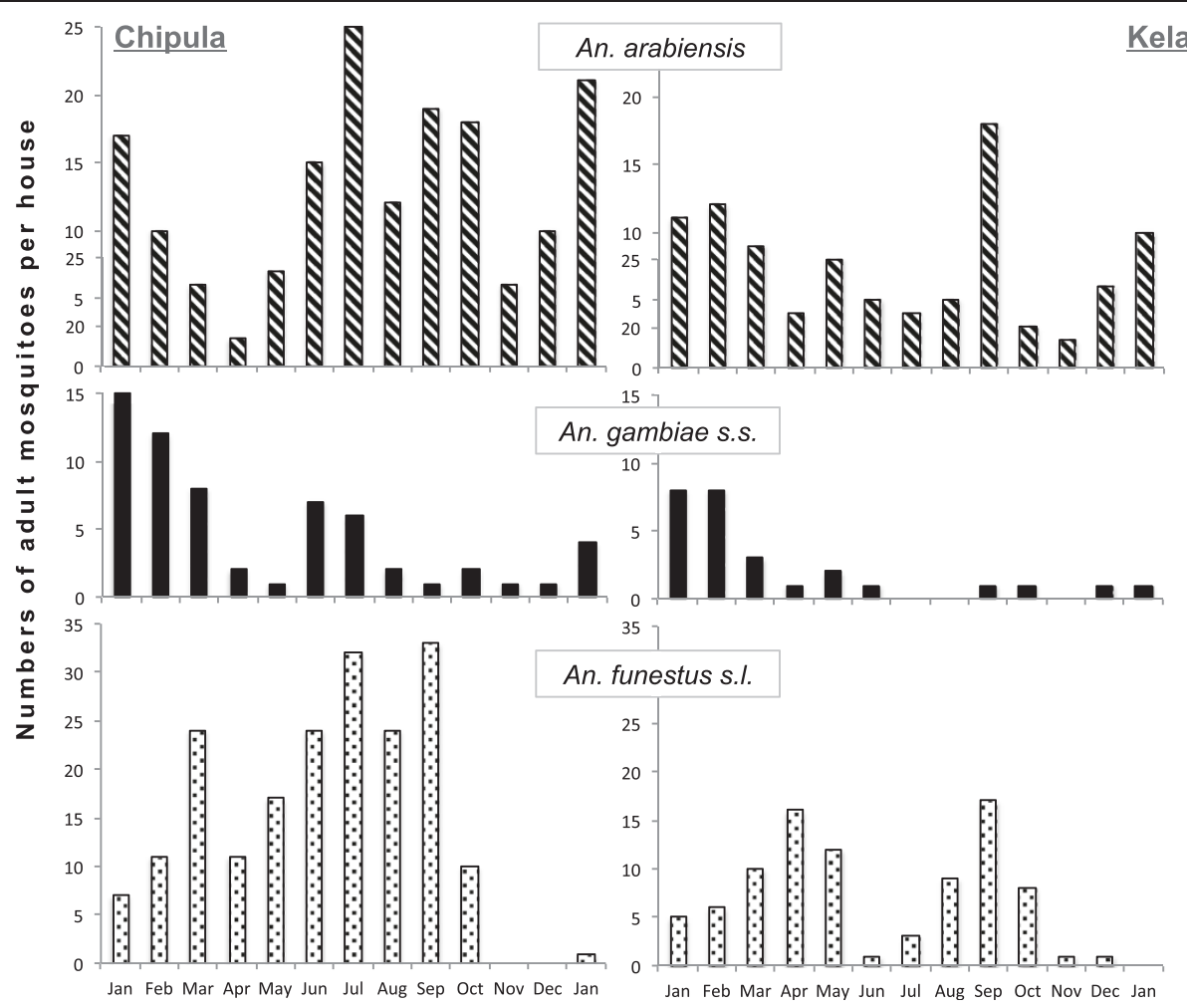

Figure 1 Monthly rainfall (black bars), maximum temperature (dotted line) and minimum temperature (dashed line) measured at Kasinthula weather station in Chikhwawa, close to the study sites and covering the same period as the data presented in Figure 1.

was granted by each village chief following an initial briefing meeting at which the nature and objectives of the study were explained to all members of the community in the local language, Chichewa. Written informed consent was obtained at the beginning of the study. On the day of mosquito sampling, the purpose of the work was again explained to each householder, and permission to enter the house was sought.

\section{Results}

Anopheline species composition

A total of 7,717 anopheline mosquito adults were collected from houses in the two study villages between January 2002 and January 2003. Only members of the An. gambiae species complex $(\mathrm{n}=4,253 ; 55.1 \%)$ and $A n$. funestus group of mosquitoes $(\mathrm{n}=3464,44.9 \%)$ were found (Table 1). The proportions of An. gambiae s.l. were slightly higher than An. funestus s.l at both study villages $\left(\mathrm{x}^{2}=6, \mathrm{df}=1, \mathrm{p}<0.013\right)$. An. gambiae s.l. comprised 57.2\% ( $\mathrm{n}=1,407)$ and An. funestus 42.8\% $(\mathrm{n}=1,054)$ of the anophelines collected at Chipula, the equivalent proportions for Kela being $54.1 \%(n=2,846)$ and $45.9 \%$ $(\mathrm{n}=2,410)$.

A total of 3,410 individual mosquitoes of the An. gambiae complex were identified to species level by PCR and three species were identified: An. arabiensis $(\mathrm{n}=2,473)$, An. gambiae s.s. $(\mathrm{n}=795)$ and An. quadriannulatus $(\mathrm{n}=14)$. The proportions of these species were similar at both villages: An arabiensis comprised $76.5 \%$ $(\mathrm{n}=831)$, An. gambiae s.s. $22.8 \%(\mathrm{n}=248)$ and An. quadriannulatus $0.7 \%(\mathrm{n}=8)$ at Chipula, and $74.8 \%(\mathrm{n}=1,642)$, $24.9 \%(\mathrm{n}=547)$ and $0.3 \%(\mathrm{n}=6)$ respectively at Kela.

No formal identifications of the An. funestus were carried out in this study. However, all 30 specimens in a sample of this species (collected from Kela village) were identified as An. funestus s.s. (Besansky, pers. communication) [27].

Table 1 Total numbers of Anopheles adult female mosquitoes collected by pyrethrum knockdown catch from houses in two villages, Chipula and Kela, in the lower Shire valley, Malawi, between January 2002 and January 2003

\begin{tabular}{lccc}
\hline Species & Chipula & Kela & Total \\
\hline An. funestus & 1054 & 2410 & 3464 \\
\hline An. gambiae s.l. & 1407 & 2846 & 4253 \\
\hline An. arabiensis & $831(76.5 \%)$ & $1642(74.8 \%)$ & 2437 \\
\hline An. gambiae s.s. & $248(22.8 \%)$ & $547(24.9 \%)$ & 795 \\
\hline An. quadriannulatus & $8(0.7 \%)$ & $6(0.3 \%)$ & 14 \\
\hline
\end{tabular}




\section{Seasonal variation in species abundance}

The three most common anophelines, An. funestus, An. arabiensis and $A n$. gambiae s.s., were present throughout the entire collection period, although the relative abundance varied markedly in different months (Figure 2).

Anopheles arabiensis was the predominant species in all catches, in Chipula ranging from 59\% $(n=121 / 205)$ of the total monthly catch (i.e. total number of all anopheline mosquitoes caught) in January 2002 to $97 \%(n=34)$ in August 2002, and in Kela ranging from 44\% $(n=52)$ in March 2002 to 93.6\% $(n=204)$ in September 2002 for Chipula and Kela respectively.

Anopheles gambiae s.s. proportions in Chipula varied from 2.9\% $(n=1)$ in August 2002 to $42 \%(n=88)$ in January 2002, and in Kela varied from $6.4 \%(n=14)$ in September 2002 to $56 \%(\mathrm{n}=66)$ in March 2002. Unlike An. arabiensis and An. funestus, more adults of An. gambiae s.s. were found during the wet season when both minimum and maximum temperatures were also high (Figure 1).

The proportions of adult female $A n$. funestus in monthly catches ranged from $76 \%(\mathrm{n}=193)$ in April 2002 to $2.9 \%(\mathrm{n}=4)$ in January 2003 in Chipula, and from 74\% ( $n=129)$ in April 2002 to $2 \%(n=2)$ in November \& December 2002 in Kela (Figure 2). At both sites An. funestus s.l. numbers were greatest during the drier months (March to September) when temperatures were also slightly lower (Figure 1).

\section{Sources of mosquito blood meals}

A total of 2,300 mosquito blood meal specimens were collected for identification, a random sample of which $(\mathrm{n}=883 ; 38.4 \%)$ were analysed by ELISA to identify the source of the ingested blood (Table 2). Humans were the most common blood meal source for all mosquitoes (92.8\%; $n=819)$, with only $5.3 \%(n=47)$ feeding on cattle. Only $5 / 883(0.6 \%)$ blood meals were from both hosts.

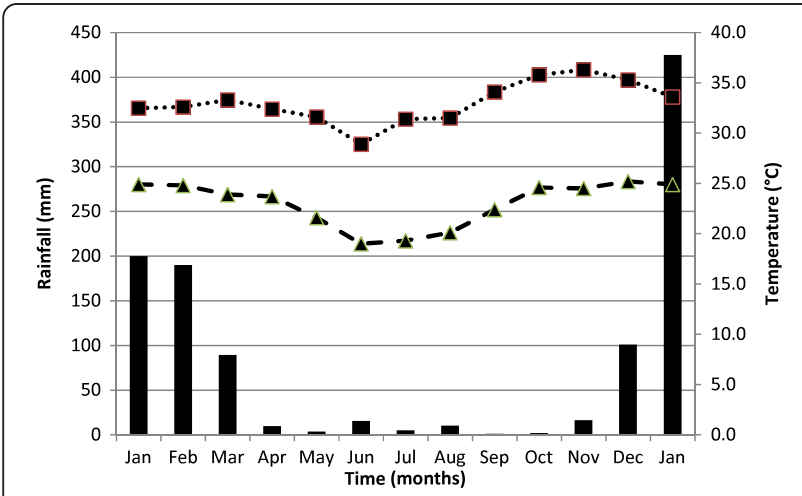

Figure 2 Monthly abundance of An. arabiensis, An. gambiae s.s. and An. funestus from Chipula and Kela in the lower Shire valley, as measured by pyrethroid knockdown catch (Jan 2002 Jan 2003).
Twelve samples (1.4\%) were negative in both ELISAs, either because the reactions failed or possibly because the blood was derived from other hosts. A random sample of 100 specimens that tested positive for human blood was re-tested with similar results.

Figure 3 shows the human blood indices of the three vector species at both sites. Indices were very high for An. gambiae s.s (0.983 and 1) and for An. funestus (0.959 and 0.969) and slightly less for An. arabiensis (0.838, 0.861 ). In all cases, significantly more blood meals were taken from humans than from cattle, although this preference was significantly lower in $A n$. arabiensis than in the other two species (Fisher's exact test, $\mathrm{df}=6$, $\mathrm{p}<0.000)$.

\section{Plasmodium sp. oocyst rates}

A total of 7,717 adult female anophelines were dissected and oocysts were found on the midguts of 100 (1.3\%). Significantly more mosquitoes (84\%) infected with oocysts were collected from Kela village $(90.5 \% ; \mathrm{n}=656)$ than from Chipula (9.5\%; $\mathrm{n}=69)\left(\chi^{2}=11.78 ; P<0.001\right)$. The estimated number of oocysts per midgut varied from 1 to 63 and the mode was 1 oocyst per midgut; data were heavily skewed with a mean of 6 and a very large variance of 66 , and were described best by a negative binomial distribution. Oocyst rates were significantly higher in An. funestus $(1.79 \% ; \mathrm{n}=3519)$ than in $A n$. gambiae s.l $(0.88 \% ; \mathrm{n}=4198)$. The mean oocyst load was slightly higher for adult female An. gambiae s.l (7.9; 95\% CI 4.3 - 11.5) was slightly but not significantly higher than An. funestus (6.9; 95\% CI 4.6 - 9.2). The dissected oocysts were processed and used for a related study, as reported previously [16].

\section{Plasmodium spp. sporozoite rates}

Screening of 3,958 mosquitoes (2,315 An. arabiensis, 718 An. gambiae s.s. and 925 An. funestus) for Plasmodium spp. sporozoites using PCR (Table 3), identified $192(4.85 \%)$ as infected. All carried $P$. falciparum alone, except for a single An. gambiae s.s. that was infected with both P. falciparum and Plasmodium malariae. No Plasmodium ovale parasites were detected. Infective mosquitoes were found in every month with highest prevalence occurring in April. Anopheles gambiae s.s. had the highest year-round sporozoite rate of $10.6 \%$, significantly greater than both $A n$. funestus (4.5\%) and $A n$. arabiensis $(3.2 \%)(\mathrm{p}<0.05)$. The inoculation rates of $A n$. arabiensis, An. gambiae s.s and An. funestus were 5.82, 6.71 and 2.33 infective bites/person/month at Chipula and 5.45, 8.09 and 2.14 infective bites/person/month at Kela. The community in this area therefore received an estimated average of 183 infective bites/ person/ annum. In both villages, An. gambiae s.s was the most important 
Table 2 Identity of blood meals from An. arabiensis, An. gambiae s.s. and An. funestus adult female mosquitoes collected by pyrethrum knockdown catch in the lower Shire valley (Jan 2002 - Jan 2003)

\begin{tabular}{lccccc}
\hline Species & \multicolumn{5}{c}{ Blood meal source } \\
\cline { 2 - 6 } & No. tested & Bovine & Human & Bovine/Human & Other \\
\hline An. arabiensis & & $37(10.9)$ & $289(85.0)$ & $4(1.2)$ & $1(0.4)$ \\
\hline An. gambiae s.s. & 246 & $1(0.4)$ & $244(99.2)$ & 0 & 0 \\
\hline An. funestus & 297 & $9(3.0)$ & $286(96.3)$ & $\mathbf{5 ( 0 . 6 )}$ & $\mathbf{1 2 ( 1 . 4 )}$
\end{tabular}

Blood meals were screened twice by ELISA for either human blood or for bovine blood, and blood meals that were negative in both screens were classed as 'other'.

malaria vector, being responsible for $44 \%$ and $52 \%$ of the transmission at Chipula and Kela respectively.

\section{Discussion}

The results demonstrate the importance of all three of the abundant anophelines in the region, An. gambiae s.s, An. arabiensis and An. funestus, as malaria vectors driving the high levels of malaria transmission in the south of Malawi. All three vectors were present throughout the year and malaria transmission occurred in every month. The combined human blood index exceeded $92 \%$ and the P. falciparum sporozoite rate was $4.8 \%$, resulting in inoculation rates of 183 infective bites/ person per annum, or a monthly rate of $\sim 15$ infective bites/ person.

This EIR is higher than some previous estimates from Malawi where annual values of only 46.1 and 27.7 infective bites/ person/ year were recorded for Mangochi and Nsanje respectively [6] but close to those recorded in Nkhotakota in the central region of Malawi where Chiphwanya (2003) recorded sporozoite rates of $6.5 \%$, $5.2 \%$ and $4.5 \%$ in $A n$. gambiae, An. funestus and $A n$.

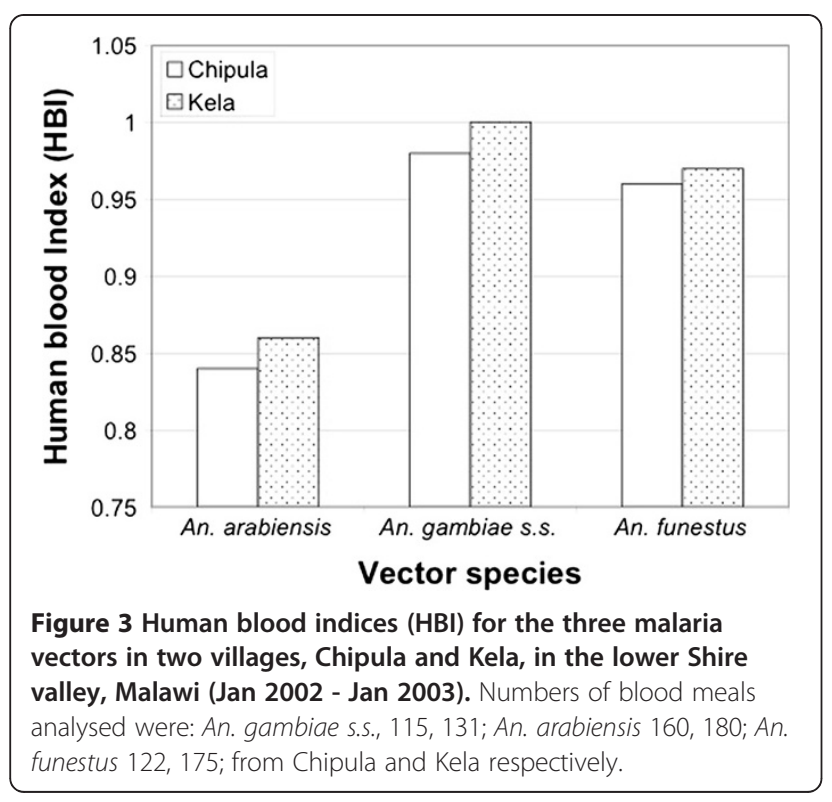

arabiensis respectively, an average sporozoite rate of $5.4 \%$ in all three vectors [8].

These rates are higher than in neighbouring Mozambique, where inoculation rates of 20 and 27 infective bites/ person/ year were recorded [28,29]. Indeed, the EIRs in this study are closer to those recorded further north in Tanzania or Kenya where values of this order or higher are common [30]. These high rates may be due, in part at least, to the use of the highly sensitive PCR method to screen mosquitoes for sporozoites as compared with microscopic examination [31]. Previously in Malawi, Chiphwanya [8] recorded comparable rates to these using ELISA. Such problems when comparing EIRs from different localities or dates have been noted previously [30,32]. Notably, the oocyst rate $(1.3 \%)$ is lower than the sporozoite rate $(4.85 \%)$. While PCR may have been highly sensitive in detection of sporozoites, it is also likely that detection of oocysts by microscopy failed to detect light infections at this stage of development, though this alone would be unlikely to account for the discrepancy between the rates.

Thus, the high EIR reported here may derive from a combination of factors, both genuine (the presence of three efficient vector species and the absence of vector control, the low availability of hosts other than humans) and potentially confounding (sensitivity of PCR in detection of Plasmodium sp. DNA, collection of endophilic anthropophilic mosquitoes only). Conversely, relying on the pyrethrum knockdown catch method meant that the study sampled only indoor resting mosquitoes. Exophilic mosquitoes would not have been caught, an important consideration if those mosquitoes were also partly zoophilic, and one that would have contributed to an underestimate of EIR. Thus in parts of Kenya, HBI values for An. arabiensis can be as low as 0.22 [33] or even 0.095 [34]. It is somewhat reassuring that HBI values comparable to ours (0.85) have been recorded in similar localities in neighbouring Zambia (0.872, 0.923, 0.94/0.96) [35-37] and Mozambique (0.985) [29]. One Zambian study found that although the relative proportions of the An. arabiensis population exhibiting endo or exophilic behaviour varied between different years, the HBI values 
Table 3 The total numbers of mosquitoes examined and sporozoite rates for An. arabiensis, An. gambiae s.s. and An. funestus collected by pyrethrum spray catch from Chipula and Kela villages in the lower Shire valley Malawi, between January 2002 and January 2003

\begin{tabular}{|c|c|c|c|c|c|c|c|}
\hline \multirow{2}{*}{+2} & \multirow{2}{*}{ Total } & \multicolumn{3}{|c|}{ Chipula village } & \multicolumn{3}{|c|}{ Kela village } \\
\hline & & No. tested & No. positive & Sporozoite rate $(95 \% \mathrm{Cl})$ & No. tested & No. positive & Sporozoite rate $(95 \% \mathrm{Cl}$ \\
\hline An. arabiensis & 2315 & 792 & 35 & $4.4(2.9-5.8)$ & 1523 & 39 & $2.6(1.8-3.4)$ \\
\hline An. gambiae s.s. & 718 & 219 & 27 & $12.3(10.2-4.4)$ & 499 & 49 & $9.8(8.2-11.5)$ \\
\hline An. funestus & 925 & 411 & 21 & $5.1(0.8-9.5)$ & 514 & 21 & $4.1(1.5-6.7)$ \\
\hline Total & 3958 & 1422 & 83 & $5.8(4.6-7.0)$ & 2536 & 109 & $4.3(3.5-5.1)$ \\
\hline
\end{tabular}

remained high [37]. These various studies are consistent with the data presented here and indicate a strong anthropophilic tendency in An. arabiensis populations in southern Malawi and neighbouring areas.

The three species: An. funestus, An. arabiensis and $A n$. gambiae s.s. fed predominantly on humans (92.8\%) as confirmed by ELISA test results. The other blood meals were taken from cattle, and were mainly in An. arabiensis $(10.9 \%)$. Few feeds (1.2\%) were of mixed origin of these two hosts. Although cows were available in both villages, they were not common (only 70 in total in both villages) and were herded into open corrals (or bomas) at night; we did not collect mosquitoes from there, although it might be expected that numbers of $A n$. arabiensis feeding on those animals could be very high. However, any potential zooprophylactic effect was not sufficient to prevent $A n$. arabiensis from feeding on humans at a frequency that resulted in a sporozoite rate of $3.2 \%$ in the endophilic proportion of its population.

The high inoculation rates reported here result, at least in part, from the presence of three competent vector species that are present all year round permitting transmission in every calendar month. The importance of An. gambiae s.s. and An. funestus in Malawi is recognised but the demonstration of high levels of transmission by An. arabiensis is in sharp contrast with current reports that it does not play a significant role in malaria transmission [12]. In fact, An. arabiensis, along with $A n$. funestus, are important in extending the duration of the malaria transmission period well beyond the wetter months. The most efficient vector, An. gambiae s.s was highly infective during the wet season i.e. between January and May 2002 with peak sporozoite rates experienced in April 2002 (late rainy season; results not shown) when high numbers of this species were found.

High EIRs, like those reported here, are associated frequently with correspondingly high prevalence rates of parasitaemia in human populations [38]. High inoculation rates can have important implications for malaria epidemiology, including the likely age at first malaria infection and the clinical disease pattern. Under high transmission intensity, children are likely to be infected at an early age, as demonstrated in a study in Mangochi in central Malawi [39] where malaria transmission is also intense, in which $60-80 \%$ of infants under 10 months of age in a cross-sectional survey were parasitaemic, the prevalence varying with season. When a high EIR causes $P$. falciparum infections to occur early in life, severe anaemia is common and is the predominating form of severe malaria among infants and toddlers [40], while those surviving to adulthood have acquired partial immunity and rarely suffer severe complications from $P$. falciparum infections.

The biggest challenge in malaria control is to reduce the observed high EIRs in order to achieve reductions in human infection rates sufficient to reduce the burden of disease. Simple but effective technologies directed against vectors - long-lasting insecticide-impregnated bed nets (LLINs) and indoor residual spraying (IRS) can dramatically reduce malaria transmission intensity. The high levels of indoor biting reported here indicate that, subject to the vectors remaining susceptible to pyrethroid and other insecticides [15,41-44], the currently planned [12] roll-out of both LLINs and IRS is likely to reduce the EIR in the Lower Shire valley. The recently reported success achieved further north in the Nkhotakhota district of Malawi supports this prospect [13]. As elsewhere in Africa, the relative importance of exophilic An. arabiensis as a malaria vector is likely to increase gradually as a consequence of control measures that reduce the contribution of endophilic mosquitoes, and the development of new measures to combat these more elusive vectors will become increasingly important.

\section{Competing interests}

The authors declare that they have no competing interests.

\section{Authors' contributions}

Conceived, designed and managed the study protocol: PJM, TM, IH, MM. Undertook the field collections and laboratory analyses: TM. Interpreted, analysed data and wrote the paper: TM, PJM, $H$. All authors read, edited and approved the final version of the manuscript.

\section{Acknowledgements}

The authors thank the villagers and village chiefs for permitting this study to be carried out in their homes, and Fred Malikebu and Ireen Chaguluka for assistance in the field. We also thank Angus Spiers, Andrea Durutti Verardi, Bob Wirtz, John Gimnig, Martin Donnelly and Harold Townson for advice and technical assistance. TM was supported by awards from the Gates 
Malaria Partnership (GMP) and UNICEF/ UNDP/World Bank/WHO Special Programme for Research and Training in Tropical Diseases (TDR).

\section{Author details}

'Liverpool School of Tropical Medicine, Liverpool, Pembroke Place, UK. ${ }^{2}$ Malawi-Liverpool Wellcome Trust Clinical Research Programme, Blantyre, Malawi. ${ }^{3}$ Malaria Alert Centre (MAC), P/ Bag 360, Chichiri, Blantyre 3, Malawi.

Received: 8 August 2012 Accepted: 8 November 2012

Published: 21 November 2012

\section{References}

1. Malawi Demographic and Health Survey 2010. Zomba: National Statistical Office; 2011. http://www.measuredhs.com/pubs/pdf/PR4/PR4.pdf.

2. Kazembe LN, Kleinschmidt I, Sharp BL: Patterns of malaria-related hospital admissions and mortality among Malawian children: an example of spatial modelling of hospital register data. Malar J 2006, 5:93.

3. Davey JB, Newstead R: Mosquitoes and other blood-sucking arthropods of the Upper Shire River. Nyasaland Ann Trop Med Parasitol 1921, 15:457-462.

4. Lamborn WA: The seasonal habit of the common anophelines of Nyasaland, with a note on its relation to the seasonal incidence of malaria. Bull Entomol Res 1924, 15:361-376.

5. Berner WA: Mosquitoes of the Shire River system, Nyasaland. Ann Entomol Soc America 1955, 48:214-218.

6. Hawley WA, Sexton JD, Tambala P, Macheso A, Zimba C, Chitsulo L, Nyanwayu D, Nyasulu Y, Franco C, Kazembe P: Malaria vector assessment, Malawi: Oct 1991 - Sept 1992. USAID, Lilongwe, Malawi: Unpublished report; 1992.

7. Spiers AA, Mzilahowa T, Atkinson D, McCall PJ: The malaria vectors of the Lower Shire Valley, Malawi. Malawi Med J 2002, 14:4-7.

8. Chiphwanya JA: Evaluation of insecticide susceptibility in malaria vector mosquitoes and their role in malaria transmission in central Malawi. Johannesburg: University of Witwatersrand; 2003.

9. Merelo-Lobo AR, McCall PJ, Perez MA, Spiers AA, Mzilahowa T, Ngwira B, Molyneux DH, Donnelly MJ: Identification of the vectors of lymphatic filariasis in the Lower Shire Valley, southern Malawi. Trans R Soc Trop Med Hyg 2003, 97:299-301.

10. Wilson ML, Walker ED, Mzilahowa T, Mathanga DP, Taylor TE: Malaria elimination in Malawi: research needs in highly endemic, povertystricken contexts. Acta Trop 2012, 121:218-226.

11. Mathanga DP, Walker ED, Wilson ML, Ali D, Taylor TE, Laufer MK: Malaria control in Malawi: current status and directions for the future. Acta Trop 2012, 121:212-217.

12. President's Malaria Initiative: Malaria Operational Plan (MOP) Malawi Year Five - FY2011. 2011. http://www.pmi.gov/countries/mops/fy11/malawi_ mop-fy11.pdf.

13. Skarbinski J, Mwandama D, Wolkon A, Luka M, Jafali J, Smith A, Mzilahowa T, Gimnig J, Campbell C, Chiphwanya J: Impact of indoor residual spraying with lambda-cyhalothrin on malaria parasitemia and anemia prevalence among children less than five years of age in an area of intense, year-round transmission in Malawi. AmJTrop Med Hyg 2012, 86:997-1004.

14. Mzilahowa T, Ball AJ, Bass C, Morgan JC, Nyoni B, Steen K, Donnelly MJ, Wilding CS: Reduced susceptibility to DDT in field populations of Anopheles quadriannulatus and Anopheles arabiensis in Malawi: evidence for larval selection. Med Vet Entomol 2008, 22:258-263.

15. Hunt R, Edwardes M, Coetzee M: Pyrethroid resistance in southern African Anopheles funestus extends to Likoma Island in Lake Malawi. Parasit Vectors 2010, 3:122.

16. Mzilahowa T, McCall PJ, Hastings IM: "Sexual" population structure and genetics of the malaria agent P. falciparum. PLoS One 2007, 2:e613.

17. Brabin B, Prinsen-Geerligs P, Verhoeff F, Kazembe P: Reducing childhood mortality in poor countries: anaemia prevention for reduction of mortality in mothers and children. Trans R Soc Trop Med Hyg 2003, 97:36-38.

18. Calis CJ, Phiri KS, Faragher EB, Brabin BJ, Bates I, Cuevas LE, de Haan RJ, Phiri Al, Malange $P$, Khoka M: Factors associated with severe anaemia in Malawian children. New Engl J Med 2008, 358:888-899.

19. Nielsen NO, Makaula P, Nyakuipa D, Bloch P, Nyasulu Y, Simonsen PE: Lymphatic filariasis in Lower Shire, southern Malawi. Trans R Soc Trop Med Hyg 2002, 96:133-138.
20. WHO: Manual on Practical Entomology. Part Il. Methods and Techniques. Geneva: World Health Organization; 1975

21. Gillies MT, Coetzee M: A supplement to the Anophelinae of Africa south of the Sahara (Afrotropical Region). Johannesburg: The South African Institute for Medical Research; 1987

22. Gillies MT, de Meillon B: The Anophelinae of Africa south of the Sahara (Ethiopian Region). Johannesburg: The South African Institute for Medical Research; 1968.

23. Collins FH, Mendez MA, Rasmussen MO, Mehaffey PC, Besansky NJ, Finnerty $\mathrm{V}$ : A ribosomal RNA gene probe differentiates member species of the Anopheles gambiae complex. AmJTrop Med Hyg 1987, 37:37-41.

24. Scott JA, Brogdon WG, Collins FH: Identification of single specimens of the Anopheles gambiae complex by the polymerase chain reaction. AmJTrop Med Hyg 1993, 49:520-529.

25. Beier JC, Perkins PV, Wirtz RA, Koros J, Diggs D, Gargan TP 2nd, Koech DK: Blood meal identification by direct enzyme-linked immunosorbent assay (ELISA), tested on Anopheles (Diptera: Culicidae) in Kenya. J Med Entomol 1988, 25:9-16

26. Snounou G, Viriyakosol S, Zhu XP, Jarra W, Pinheiro L, do Rosario VE, Thaithong S, Brown KN: High sensitivity of detection of human malaria parasites by the use of nested polymerase chain reaction. Mol Biochem Parasitol 1993, 61:315-320.

27. Koekemoer LL, Lochouarn L, Hunt RH, Coetzee M: Single-strand conformation polymorphism analysis for identification of four members of the Anopheles funestus (Diptera: Culicidae) group. J Med Entomol 1999 36:125-130.

28. Mendis C, Jacobsen JL, Gamage-Mendis A, Bule E, Dgedge M, Thompson R, Cuamba N, Barreto J, Begtrup K, Sinden RE, Høgh B: Anopheles arabiensis and $A n$. funestus are equally important vectors of malaria in Matola coastal suburb of Maputo, southern Mozambique. Med Vet Entomol 2000, 14:171-180

29. Thompson R, Begtrup K, Cuamba N, Dgedge M, Mendis C, Gamage-Mendis A, Enosse SM, Barreto J, Sinden RE, Hogh B: The Matola malaria project: a temporal and spatial study of malaria transmission and disease in a suburban area of Maputo, Mozambique. AmJTrop Med Hyg 1997, 57:550-559.

30. Hay SI, Rogers DJ, Toomer JF, Snow RW: Annual Plasmodium falciparum entomological inoculation rates (EIR) across Africa: literature survey, Internet access and review. Trans R Soc Trop Med Hyg 2000, 94:113-127.

31. Wilson MD, Ofosu-Okyere A, Okoli AU, McCall PJ, Snounou G: Direct comparison of microscopy and polymerase chain reaction for the detection of Plasmodium sporozoites in salivary glands of mosquitoes. Trans R Soc Trop Med Hyg 1998, 92:482-483.

32. Kelly-Hope LA, McKenzie FE: The multiplicity of malaria transmission: a review of entomological inoculation rate measurements and methods across sub-Saharan Africa. Malar J 2009, 8:19.

33. Githeko AK, Service MW, Mbogo CM, Atieli FK, Juma FO: Plasmodium falciparum sporozoite and entomological inoculation rates at the Ahero rice irrigation scheme and the Miwani sugar-belt in western Kenya. Ann Trop Med Parasitol 1993, 87:379-391.

34. Ijumba JN, Mwangi RW, Beier JC: Malaria transmission potential of Anopheles mosquitoes in the Mwea-Tebere irrigation scheme, Kenya. Med Vet Entomol 1990, 4:425-432.

35. Fornadel CM, Norris DE: Increased endophily by the malaria vector Anopheles arabiensis in southern Zambia and identification of digested blood meals. AmJTrop Med Hyg 2008, 79:876-880.

36. Kent RJ, Thuma PE, Mharakurwa S, Norris DE: Seasonality, blood feeding behavior, and transmission of Plasmodium falciparum by Anopheles arabiensis after an extended drought in southern Zambia. AmJTrop Med Hyg 2007, 76:267-274.

37. Fornadel CM, Norris LC, Glass GE, Norris DE: Analysis of Anopheles arabiensis blood feeding behavior in southern Zambia during the two years after introduction of insecticide-treated bed nets. AmJTrop Med Hyg 2010, 83:848-853.

38. Beier JC, Killeen GF, Githure Jl: Entomologic inoculation rates and Plasmodium falciparum malaria prevalence in Africa. AmJTrop Med Hyg 1999, 61:109-113.

39. Slutsker L, Khoromana CO, Hightower AW, Macheso A, Wirima JJ, Breman JG, Heymann DL, Steketee RW: Malaria infection in infancy in rural Malawi. AmJTrop Med Hyg 1996, 55(1 Suppl):71-76.

40. Snow RW, Bastos de Azevedo I, Lowe BS, Kabiru EW, Nevill CG, Mwankusye S, Kassiga G, Marsh K, Teuscher T: Severe childhood malaria 
in two areas of markedly different falciparum transmission in east Africa. Acta Trop 1994, 57:289-300.

41. Chanda E, Hemingway J, Kleinschmidt I, Rehman AM, Ramdeen V, Phiri FN, Coetzer S, Mthembu D, Shinondo CJ, Chizema-Kawesha E, Kamuliwo M,

Mukonka V, Baboo KS, Coleman M: Insecticide resistance and the future of malaria control in Zambia. PLoS One 2011, 6:e24336.

42. Cuamba N, Morgan JC, Irving H, Steven A, Wondji CS: High level of pyrethroid resistance in an Anopheles funestus population of the Chokwe District in Mozambique. PLoS One 2010, 5:e11010.

43. Kloke GR, Nhamahanga E, Hunt RH, Coetzee M: Vectorial status and insecticide resistance of Anopheles funestus from a sugar estate in southern Mozambique. Parasit Vectors 2011, 4:16.

44. Morgan JC, Irving H, Okedi LM, Steven A, Wondji CS: Pyrethroid resistance in an Anopheles funestus population from Uganda. PLOS One 2010, 5:e11872.

doi:10.1186/1475-2875-11-380

Cite this article as: Mzilahowa et al: Entomological indices of malaria transmission in Chikhwawa district, Southern Malawi. Malaria Journal 2012 11:380

\section{Submit your next manuscript to BioMed Central and take full advantage of:}

- Convenient online submission

- Thorough peer review

- No space constraints or color figure charges

- Immediate publication on acceptance

- Inclusion in PubMed, CAS, Scopus and Google Scholar

- Research which is freely available for redistribution 